\title{
A unidade teórico-prática da intervenção didático-formativa no contexto da docência
}

\section{The theoretical-practical unit of the didactic-formative intervention in the context of teaching}

\author{
Patrícia Lopes Jorge Franco ${ }^{1}$ \\ https://orcid.org/0000-0002-7774-4089 \\ Andréa Maturano Longarezi ${ }^{2}$ \\ https://orcid.org/0000-0002-5651-9333 \\ Fabiana Fiorezi De Marco ${ }^{3}$ \\ https://orcid.org/0000-0002-7126-5626
}

\begin{abstract}
Resumo: A temática abarca a unidade teórico-prática da ação didático-formativa na docência de uma professora de Matemática e de estudantes do ensino fundamental em uma escola pública. Pesquisa longitudinal à luz da teoria histórico-cultural, método materialista histórico-dialético, cuja orientação teóricometodológica favorece que sujeitos inter-relacionem suas atividades de ensino e de estudo na intervenção didático-formativa. Neste artigo o objetivo é discutir como a organização do ensino para o desenvolvimento do pensamento científico-teórico dos estudantes se constitui como conteúdo-forma no processo de desenvolvimento dos envolvidos. Resultados apontam que a professora apresenta desenvolvimento da ação mental sobre a docência, oferecendo elementos didáticos capazes de orientar estudantes a pensar e agir mediante a essência dos conceitos científicos na Álgebra. Alguns alcançaram certo domínio dos meios e das ações mentais lógicas do movimento interno representado pelo conceito teórico de funções e de equações lineares e quadráticas, a partir da essência de elos e nexos que os compõem.
\end{abstract}

Palavras-chave: Ensino de matemática. Teoria histórico-cultural. Lógica dialética. Pensamento teórico. Didática desenvolvimental.

\begin{abstract}
The topic concerns the theoretical-practical unit of didactic-formative interventions in the teaching by a Mathematics teacher, and of elementary school students in a public school. This longitudinal research was carried out in the light of the historical-cultural, historical-dialectical materialist method, whose theoretical and methodological orientation favors subjects' interrelating their teaching and study activities in didactic-formative interventions. In this article, the objective is to discuss how the organization of teaching for the development of scientific-theoretical thought among students is constituted as content-form in the developmental process of the individuals involved. Results show that the teacher presents the development of the mental action on teaching, offering didactic elements that can guide students to think and act through the essence of scientific concepts in Algebra. Some students achieve a certain mastery of the logical mental means and actions of the internal movement represented by the theoretical concept of functions and linear and quadratic equations from the essence of the links and nexus that compose them.
\end{abstract}

Keywords: Mathematics teaching. Historical-cultural theory. Dialectical logic. Theoretical thinking. Developmental didactics.

\footnotetext{
${ }^{1}$ Universidade do Estado de Minas Gerais (UEMG), Departamento de Licenciatura em Ciências Biológicas e Química. Unidade Ituiutaba, MG, Brasil. E-mail: patricia.franco@uemg.br

${ }^{2}$ Universidade Federal de Uberlândia (UFU), Faculdade de Matemática, Uberlândia, MG, Brasil.

${ }^{3}$ UFU, Centro de Ciências Exatas e Tecnologia, Faculdade de Matemática, Uberlândia, MG, Brasil.
} 


\section{Introdução}

As discussões empreendidas neste artigo articulam-se ao estudo dos elementos teóricometodológicos da teoria histórico-cultural da atividade (THCA) (PUENTES; LONGAREZI, 2017), da Didática Desenvolvimental (DD) e do método histórico-dialético (MHD), na intervenção didático-formativa (IDF) como formação docente e discente, como unidade teórico -prática e conteúdo-forma, realizada no contexto da docência, ou seja, na sua relação com o trabalho educativo.

O estudo em questão fez parte de uma pesquisa de doutorado desenvolvida com uma professora de matemática e uma classe de 21 estudantes do ensino fundamental II (EF-II). Por se tratar de uma pesquisa longitudinal, a mesma professora e os mesmos estudantes mantiveram-se como sujeitos ativos da IDF em 2012 (durante um semestre letivo do 8. ${ }^{\circ}$ ano escolar) e em 2013 (durante dois semestres letivos do 9. ${ }^{\circ}$ ano), em uma escola pública municipal de Ituiutaba, estado de Minas Gerais.

A pesquisa teve como finalidade apreender os processos de formação e desenvolvimento, os motivos da professora e dos estudantes na atividade pedagógica, particularmente na formação de determinados conceitos matemáticos no campo da álgebra, tais como: equações fracionárias, equações lineares, quadráticas e funções. Assim, buscou-se relacionar de forma dialética o estudo e a organização do ensino, com o objetivo de apreender as ações didáticas impulsionadoras de desenvolvimento dos estudantes e da professora, para obter condição de atividade. Por atividade entende-se "processos específicos que exercem uma ou outra relação vital, quer dizer, ativa, entre sujeito e a realidade" (LEONTIEV, 1974, p. 43, tradução nossa). Esse conceito será mais detalhado na próxima seção.

Nesse contexto, tomaram-se as seguintes questões:

Seria possível estabelecer outras relações na estrutura interna das atividades (estudo e ensino) com as condições da educação pública brasileira?

Que ações didáticas e formativas seriam necessárias para a constituição de relações mais favoráveis ao desenvolvimento de motivos que formam o sentido dessas atividades?

Neste artigo, em particular, buscou-se apresentar o entendimento dessas questões, partindo da discussão de uma IDF desenvolvida pela professora com estudantes em uma escola pública, como mencionado anteriormente, na sua relação com o trabalho educativo.

Por isso, inicialmente desenvolve-se o conceito de atividade, no sentido atribuído por Leontiev (1978), para dar visibilidade à importância desse aporte na construção do que se propôs. Em seguida, apresenta-se uma breve descrição da problemática em que se insere este estudo, seus desdobramentos nas práticas pedagógicas e as novas perspectivas que se vislumbram para o tratamento dessa temática. Na sequência, discorre-se sobre o método e a organização da IDF, impulsionadores do desenvolvimento da professora e dos estudantes. Por fim, se evidenciam os indícios de resistências, rupturas e elementos do desenvolvimento dos sujeitos, que sinalizam as possibilidades desse caminho na busca para superar processos de formação docente e discente dicotômicos e, por vezes, alienantes. 


\section{Atividade e formação de professores: delineando o sentido e a orientação da intervenção didático-formativa como abordagem teórico-metodológica}

O conceito de atividade de Alexis Nikolaevich Leontiev (LEONTIEV, 1978, 2001) vincula-se ao modo como a psique humana se desenvolve e está determinada pelo próprio processo de vida real do homem. O postulado da diretividade, como movimento previsto na perspectiva reflexológica, numa relação estímulo-resposta entre sujeito e objeto, passa a ser questionado e substituído, pelos estudiosos da THCA (PUENTES; LONGAREZI, 2017), por um novo esquema relacional, no qual se tem a atividade do sujeito como premissa e finalidade nos processos de formação e desenvolvimento humano. Conforme Leontiev (2001), a atividade envolve os componentes presentes nas relações por ora estabelecidas, numa versão limitada ao estímulo e à resposta, porém, agora como mediadora das conexões até então presentes. Há aí uma verdadeira revolução na forma de conceber os processos de constituição humana. Por esse prisma, o referido autor sinaliza que a atividade orienta o sujeito no mundo, nas condições reais e concretas do homem, em um sistema de relações sociais, sem o qual essa mesma atividade humana não existiria. O desenvolvimento da psique humana está, contudo, diretamente ligado ao lugar que o sujeito ocupa no sistema de relações sociais, pois depende das condições em que vive e da atividade que realiza.

Leontiev (1978) defende que alguns tipos de atividade são mais determinantes no desenvolvimento do psiquismo, e outros exercem papel secundário. Cada estágio do desenvolvimento da psique é determinado pela relação dominante do sujeito com a realidade, com o tipo de atividade dominante para ele no período. Atividade dominante é, assim, entendida como aquela que exerce forças motoras psíquicas, e não aquela na qual o sujeito fica envolvido a maior parte do tempo. A partir desse entendimento, essa atividade influencia as principais mudanças nos processos psíquicos, de modo que, a cada etapa da vida psíquica, surge uma contradição interna causada pela mudança de lugar do sujeito no sistema de relações sociais e pela mudança do conteúdo da atividade essencial nesse período. $\mathrm{Na}$ atividade existe uma relação triádica (sujeito-atividade-objeto), constituindo-se historicamente na vida em sociedade, nos processos de trabalho coletivo e de necessidades humanas orientadas por finalidades.

Nessa concepção, a atividade não existe sem o objeto que lhe corresponda, pois é ele que determina a direção que a atividade pode ter na vida do sujeito, considerando o lugar social ocupado por ele na sociedade e as relações que, assim, estabelece com o mundo. Por isso, o que diferencia uma atividade da outra não é tão somente sua forma externa, seu modo de realização, sua tensão emocional, mas o motivo que a orienta, ou seja, o objeto para o qual se direciona (LEONTIEV, 1974). Nesse sentido se estabelece uma inter-relação substancial entre necessidade, motivo, objeto e objetivo do sujeito, dentro de um sistema de relações sociais.

No conjunto de tais atividades, a dominante é aquela que impulsiona o desenvolvimento da psique, orientada por finalidades oriundas das necessidades de uma prática social. Por essa razão, analisa-se o desenvolvimento docente como uma prática social que realiza as mediações desse sujeito com o mundo e consigo mesmo, em seu aspecto pessoal e profissional. Nessa perspectiva, entende-se que o professor se forma e se desenvolve como profissional 
a partir da apropriação de saberes e práticas educativas, no âmbito da docência, na inter-relação indivíduo-sociedade mediante a atividade, no contexto humano-social, e não somente nas licenciaturas destinadas para esse fim. Dessa forma, a formação docente e discente pressupõe intencionalidade política, ética e didática em relação ao desenvolvimento das especificidades humanas, engendradas pelas condições socioculturais, mediadas pelas diversas relações com os outros e o mundo.

Entretanto, no contexto brasileiro, a formação docente tem historicamente se apresentado de diferentes formas. Pesquisas apontam que em sua trajetória existiram diferentes conceitos e práticas permeando os espaços de formação dos professores, em busca de atender a diferentes interesses e finalidades. De acordo com Alvarado-Prada, Freitas e Freitas (2010), na década de 1930 buscou-se atender a interesses ideológico-políticos e, para combater os nacionalismos, a cooptação e a propagação de propostas pedagógicas tornaram-se necessárias. Assim, por meio da incorporação de métodos e treinamentos de recursos humanos, despidos das características regionais e sociais, a formação docente se instituiu como paliativo, e estendeu-se também até o período pós-Segunda Guerra Mundial.

Para Coraggio (1996), a partir de então, o processo de capacitação de recursos humanos para implantação das reformas educativas tornou-se evidente na América Latina. Nas décadas de 1960 a 1980, no auge da Guerra Fria, os cursos esporádicos foram práticas recorrentes, e deles surgiram terminologias como "capacitação", "treinamento", "reciclagem", "aplicação", "monitoramento" e "qualificação" (ALVARADO PRADA, 1997). No entanto, de forma qualitativa, efetivamente, tais cursos pouco acrescentaram ao desenvolvimento humano.

Nos termos anteriormente apresentados, a formação docente de modo continuado estabeleceu-se para atender aos interesses do Estado como consequência da globalização e da meritocracia (CORAGGIO, 1996). Esse tipo de formação docente constituiu-se corolário das parcerias entre público e privado, porque passou a ser adquirida ou comprada pelo próprio professor. Percebe-se que nas diferentes situações se encontram os fundamentos da concepção consumista e tecnicista de educação. Como expressividade de tais orientações ideológicas, as políticas materializadas na contemporaneidade se orientam por dimensões pragmáticas da formação de professores (FREITAS, 1992).

Pesquisas (FRANCO, 2009; FRANCO; LONGAREZI, 2011; FRANCO; SOUSA, 2018; FRANCO; LONGAREZI; MARCO, 2015, 2016, 2017, 2018; LONGAREZI; FRANCO, 2013, 2017; RODRIGUES; FRANCO; BUÊNCIO, 2018) têm revelado a cisão entre significado social e sentido pessoal das ações de formação de professores, na perspectiva dos próprios sujeitos do processo. Esses estudos, orientados por uma abordagem históricocultural da atividade (PUENTES; LONGAREZI, 2017), evidenciam que os motivos da cisão geralmente ocorrem pela não satisfação das necessidades formativas no objeto da ação, pois o conteúdo e as formas (os instrumentos mediadores), em muitas dessas ações formativas, não se correspondem. Em tais condições, as significações e os sentidos passam a ser contraditórios.

A realidade educacional brasileira é expressão de um contexto bastante paradoxal: em muitos casos, as secretarias municipais e estaduais de educação ofertam ações de formação continuada aos professores na mesma proporção em que se acentua o descontentamento desses em relação às condições e ao conteúdo do que está sendo ofertado. Essas pesquisas (FRANCO, 2009; FRANCO; LONGAREZI, 2011; FRANCO; SOUSA, 2018; FRANCO; LONGAREZI; MARCO, 2015, 2016, 2017, 2018; LONGAREZI; FRANCO, 2013, 2017; 
RODRIGUES; FRANCO; BUÊNCIO, 2018) têm demonstrado a estreita relação entre motivos, necessidades e condições objetivas e subjetivas da atividade educativa que não se correspondem, com fortes impactos na composição dos motivos dos professores.

Fica evidente que a profissão docente não pode ser considerada como algo pronto e acabado, que se adquire somente na certificação. Torna-se imprescindível a construção de outra lógica de desenvolvimento profissional dos professores, na qual esses não sejam responsabilizados pelos fracassos do sistema de ensino.

Nesse contexto, emerge uma questão da qual não se pode esquivar: como esperar que o docente desenvolva uma prática pedagógica que permita ao estudante o desenvolvimento conceitual nas diferentes áreas do conhecimento, quando ele próprio não se formou conceitualmente?

Orientado por tal indagação, o artigo defende que o processo de formação docente e discente necessita situar-se no terreno do desenvolvimento humano na prática social e, como tal, considerar trabalho (docência) e formação (desenvolvimento) como unidade dialética.

Nesse caso, as atividades de ensino e estudo são tomadas como unidade, ou seja, como obutchénie, pois Longarezi e Puentes (2017, p. 7) explicam que na cultura russa essa palavra "expressa justamente a unidade constitutiva da atividade [...] que encerra tanto a atividade didática do professor quanto a atividade de autotransformação dos alunos". Assim, compreende-se que no procedimento de IDF o docente organiza a sua atividade, tendo em vista a atividade de estudo dos estudantes sobre o objeto do conhecimento científico, e como resultado pode-se produzir apropriação do conceito teórico. E o conteúdo e a forma dessa apropriação necessitam ser tomados como objeto de análise por parte dos professores, porque saber orientar o estudante para pensar-agir teoricamente vai muito além de transmitir conteúdos escolares.

Para Petrovsky (1986, p. 292, tradução nossa) “[...] o pensamento é um processo ativo do sujeito sobre o mundo objetivo em conceitos, juízos, teorias, etc”. Porquanto, orientar o estudante nesse processo se constitui fundamental na escola. Entendendo que "[...] ter um conceito sobre um ou outro objeto significa saber reproduzir mentalmente seu conteúdo, construí-lo. A ação de construção e transformação do objeto mental constitui o ato de sua compreensão e explicação, o descobrimento de sua essência (DAVYDOV, 1988, p. 126, tradução nossa). Isso significa dizer que a educação escolarizada deveria estar preocupada em saber não apenas se os estudantes dominam ou não os conteúdos escolares que lhes transmitem, mas também se os estudantes sabem pensar conceitualmente e como a educação pode contribuir com esse processo.

No processo de apropriação de conceitos teóricos existem etapas de ações (GALPERIN, 2001) para o sujeito realizar, capazes de o auxiliar nessa apropriação e no desenvolvimento mental. A primeira etapa é a da ação materializada ou material, a segunda é a da linguagem (externa e interna) e a terceira é a da ação mental. Esse percurso (do objetal ao mental) se efetiva a partir de uma base de orientação (BOA), compreendida como aquela que se forma sobre a análise das relações da área dada, da ordenação do material - do geral ao particular.

A problemática assim apresentada reforça a relação entre processo e produto e os fins da educação escolarizada, evidenciando que não cabe a separação entre objetivo-meio e objetivo-fim, pois os objetivos precisam estar imbricados uns nos outros na educação escolarizada. Por conseguinte, eles podem ser tomados como unidade teórico-prática e conteúdo-forma da formação docente e discente. 
Franco, P. L. J.; Longarezi, A. M.; De Marco, F. F.

Por aqui, vislumbra-se a abordagem teórico-metodológica a partir da qual se propõe o enfrentamento das questões do ensino escolarizado no Brasil, principalmente no que se refere aos processos de humanização, tendo em vista a prática social em um contexto concreto. Ao mesmo tempo, tal abordagem se revela como um enorme desafio para todos os envolvidos, dada a complexidade e a profundidade desse tipo de formação docente e discente, pois implica enfrentar as contradições, provocar os confrontos, lidar com as resistências e os embates inerentes às tensões que emergem dos diferentes sujeitos, nos vários contextos nos quais se inserem.

\section{A unidade pesquisa, a atividade de ensino e estudo - obutchénie - na intervenção didático-formativa: a metodologia investigativa}

A “intervenção didático-formativa" (IDF) é um tipo de pesquisa desenvolvida no Brasil por um grupo de pesquisadores no contexto do Grupo de Estudos e Pesquisas em Didática e Desenvolvimento Profissional de Professores (GEPEDI) na Universidade Federal de Uberlândia (UFU) (FERREIRA, 2017a, 2017b, 2018; FRANCO, 2015; FRANCO; SOUZA; FEROLA, 2018; GERMANOS, 2016; LONGAREZI, 2012, 2014, 2017; LONGAREZI; FERREIRA, 2019; LONGAREZI; MOURA, 2017; SOUSA, 2016), para a realização de investigações com a DD (FEROLA, 2016; FERREIRA, 2017c; FRANCO, 2015; GERMANOS, 2016; SOUSA, 2016; SOUZA, 2016) alicerça-se no MHD e na THCA (PUENTES; LONGAREZI, 2017). Por isso, implica atitude ativa e criativa de professores, estudantes e pesquisadores em suas práticas sociais. Em sua essência essa metodologia apresenta "[...] como objetivo-fim o desenvolvimento dos estudantes pela atividade de estudo (objetivo-meio) [...]" (LONGAREZI, 2014, p. 15). No sentido procedimental, organiza-se,

[...] em quatro etapas: 1) diagnóstico dos processos de ensino-aprendizagem-desenvolvimento vigentes nos contextos escolares; 2) ações formativas junto aos docentes; 3) ações educativas junto aos discentes; e 4) sistematização e análise dos princípios didáticos norteadores de um ensino que desencadeia desenvolvimento[...]. (LONGAREZI, 2012, p. 19)

A organização da pesquisa se efetiva no processo de organização do ensino, e esse, por sua vez, no de organização do estudo dos estudantes (ações de aprendizagem), durante todo o período da investigação realizado no contexto escolar.

Em uma das pesquisas (FRANCO, 2015) realizada pelo Grupo de Estudos e Pesquisas em Didática Desenvolvimental e Profissionalização Docente, foi selecionada uma professora de matemática, efetiva da rede pública de ensino no estado de Minas Gerais, que manifestou a necessidade de rever suas práticas pedagógicas. A partir do pressuposto de que a necessidade, no sentido atribuído por Leontiev, deve ser do sujeito e estar orientada para resolver algum problema teórico-prático de sua prática social - no caso, ensino -, nada mais coerente do que depreender do próprio sujeito sua necessidade docente e formativa; essa foi, pois, a principal razão que levou à seleção dessa professora: 
Eu tenho 23 anos de docência e durante todo esse percurso o que eu acho mais difícil e angustiante é a aprendizagem dos meus alunos, sempre fui preocupada mesmo. Esse desinteresse realmente me preocupa. Às vezes, eu fico me cobrando muito e me questiono: Será como é que eu tenho que dar as minhas aulas? Será que despertar esse interesse não é importante? Muitas vezes, meus colegas de profissão me criticam sobre isso, porque eu penso de um jeito e eles pensam de outro. Alguns dizem para eu deixar isso pra lá, que as coisas são assim mesmo, não importa tanto se eles estão tirando nota ruim, dizem até que com o tempo eles [os alunos] vão recuperando. Mas eu não consigo pensar assim, eu quero saber e investigar o motivo, participar um pouco mais da vida do meu aluno, não só da vida escolar. (FRANCO, 2015, p. 115).

Nesse contexto, foi a professora quem selecionou a classe de estudantes que participaria das atividades de intervenção; uma turma considerada por ela como apática para os estudos e com inúmeras dificuldades na área de matemática. No período de três semestres letivos a professora se envolveu em leituras, estudos, diálogos sobre o aporte teórico-metodológico da THCA (PUENTES; LONGAREZI, 2017), a fim de apropriação para instrumentalização e objetivação em seu trabalho educativo. Esse processo gerou na professora contradições e conflitos em seu modo de organizar o ensino e produziu movimentos de resistência na busca pelas superações. Aos poucos ela se dedicou ao estudo sobre os modos e as condições da aula, na tentativa de buscar o modo geral da ação de ensinar, fundamentado na THCA (PUENTES; LONGAREZI, 2017), ou seja, nos elementos didáticos do ensino, em sua unidade com a aprendizagem (objetivos, conteúdo, métodos, meios, formas de organização, avaliação), sob a lógica dialética. Ao longo da IDF a professora pôde constituir novas necessidades, na estreita relação com o motivo orientado e vinculado ao conteúdo objetivo de ensinar (FRANCO; LONGAREZI; MARCO, 2015, 2016, 2017, 2018).

No sistema de ações de aprendizagem sobre o conceito de equações fracionárias foi previsto solicitação de tarefas a serem resolvidas pelo estudante com ações lógicas e específicas, tendo em vista a compreensão dos movimentos internos presentes na constituição desse conceito: equivalência de valores; campo de variação; relações de interdependência e transitividade. No sistema de ações de aprendizagem com o conceito de equações lineares e quadráticas foram previstas tarefas para que os estudantes refletissem sobre os movimentos geral e particularizado; fluência; relações de interdependência e igualdade; propriedades da geometria e aritmética. E no sistema de ações de aprendizagem com o conceito de função foram previstas tarefas para que os estudantes analisassem as relações de interdependência entre grandezas; campo de variação; e regularidades quantitativas.

Esse enfoque didático se preocupou, ao mesmo tempo, com o processo e o produto, e ensinou-se não só um novo conceito, mas também os modos de sua apropriação. Klingberg (1978, p. 50, tradução nossa) salienta como duplo aspecto da didática “[...] o lógico [...]", que se refere aos objetivos concretos do que se tem para ensinar; e o aspecto "[...] ético, psicológico[...]", relativo aos objetivos subjetivos de como os estudantes vão se apropriar desse conceito. Isso englobou o cuidado com o processo de formação das ações mentais, dos valores, das atitudes, dos sentimentos, da relação ativa e consciente dos estudantes durante o processo 
Franco, P. L. J.; Longarezi, A. M.; De Marco, F. F.

(FRANCO, 2015). Na totalidade do movimento, desenvolveram-se 13 sistemas de ações de aprendizagem com os três conceitos. A cada sistema realizado pelos estudantes, apreenderamse as correlações entre motivo, objetivo e objeto do conhecimento científico, mediante análise dos registros reflexivos escritos e verbalizados pelos estudantes em cada momento aula.

Durante os encontros de formação da professora com a pesquisadora, coletaram-se os registros por meio de gravações em áudio, no caderno de campo da pesquisadora e em notas reflexivas da professora. Da leitura e análise desses registros, apreenderam-se produtos objetivos e subjetivos do seu processo formativo. Os dados da totalidade do processo formativo da professora, sob esse enfoque didático e dialético, organizaram-se em unidades de análise: compartilhamento/interações; atribuição de sentido; apropriação/objetivação, que, conforme Vigotski (1991), representam o movimento universal-singular-particular como indivisíveis elementos da essência investigada. Tais unidades foram evidenciadas pelos episódios, porque revelam "[...] a natureza e qualidade das ações [...]" (MOURA, 2000, p. 60) da professora.

Para atender às especificidades deste artigo, optou-se por apresentar, nos dois episódios, alguns indícios dos movimentos de resistência da professora e os de busca pela sua superação: As dificuldades de organização do ensino para além da lógica formal e $O$ pensamento analítico na construção do conceito. Os dados desses episódios foram extraídos dos encontros de formação (gravados em áudio) e das notas reflexivas da professora (redigidas por ela, ao final de cada aula dada). De modo que se apreenderam alguns indícios reveladores de como as ações do pensamento analítico (análise, reflexão, síntese, comparações sobre como formar o pensamento teórico no estudante, no ato de sua consecução -práxis) constituíram forma e conteúdo do IDF. Como relatado anteriormente, foram expressos nas unidades de análise: (a) compartilhamento/interações; (b) apropriações / objetivações; (c) atribuição de sentido. Na próxima seção, essas unidades de análise serão discutidas de modo mais detalhado.

Em decorrência desse movimento, a sala de aula se constituiu em campo de investigação didática e ajudou a elaborar conhecimento novo, ao apreender algumas ações didáticas mobilizadoras de motivos formadores de sentido em ambas as atividades, da professora e dos estudantes (FRANCO, 2015), que também serão analisadas na seção seguinte.

\section{A aprendizagem-desenvolvimento profissional da docente na unidade teórico-prática desencadeada pela intervenção didático-formativa}

A IDF se desenvolveu em momentos inter-relacionados: (i) criação de necessidades coletivas advindas da atividade teórico-prática do trabalho educativo; (ii) organização dos elementos de orientação e execução capazes de propiciar a satisfação das necessidades coletivas (professor e estudantes); (iii) planejamento de ações e tarefas de estudo para novas apropriações e objetivações no trabalho educativo: organização do ensino sob enfoque desenvolvimental; e, (iv) movimentos dialéticos de superação entre a prática, a experiência, o pseudoconceito e a teoria, o concreto pensado e generalizado, em novas situações de organização do ensino.

Na perspectiva da DD, o docente organiza o ensino de modo a oferecer aos estudantes as condições, as ferramentas e os instrumentos necessários para que eles possam desenvolver o próprio pensamento teórico, pela via da formação de conceitos e de ações mentais. Afinal, "[...] a descoberta da essência de um dado conceito precisa ser realizada pelo próprio estudante, mediante as ações organizadas intencional e previamente pelo professor" (LONGAREZI; 
FRANCO, 2016, p. 545). Mas que ações são essas que auxiliam os estudantes a apropriar-se de um conceito teórico/científico e que, ao mesmo tempo, contribuem para que ele desenvolva seu pensamento diante do conceito, tendo em vista a sua objetivação na realidade da prática social? Eis uma nova necessidade constituída na realidade concreta da docência da professora e no contexto da pesquisa, via IDF.

A necessidade se vinculou ao planejamento de atividades de ensino que pudessem formar o pensamento teórico nos estudantes. O objeto se referiu ao ensino e à didática desenvolvimental. E o motivo, inicialmente, ligou-se à possibilidade de obter a certificação, no contexto da pesquisa, via IDF. No entanto, somente no decurso do processo a professora começou a se conscientizar de que não bastava listar o conteúdo escolar a ensinar, não bastava explicar a definição formal do conceito para os estudantes, ou explicar a forma resolutiva de uma determinada situação matemática, pois tornava-se necessário orientar os estudantes para que desenvolvessem um modo de pensar sobre como se constitui determinado conceito teórico (FRANCO, 2015; FRANCO; LONGAREZI; MARCO, 2015, 2016, 2017, 2018).

Dessa maneira, os elementos orientadores da estrutura psicológica da atividade de ensino - necessidade, objeto e motivo - paulatinamente constituíram as correlações com os elementos de execução: ações, operações e objetivos, para que um novo pensar e agir pudesse se objetivar. As ações foram: (1) leituras de textos fundamentados na THCA (PUENTES; LONGAREZI, 2017) sobre educação, ensino, desenvolvimento, didática, movimento dialético, formação das ações mentais; (2) planejamento e desenvolvimento didático de ações de aprendizagem dos estudantes, envolvendo conceitos algébricos (num processo de confrontação da didática tradicional com a didática desenvolvimental); e, (3) autoavaliação (FRANCO, 2015).

Nessa estrutura interna psicológica, as operações se referiram ao modo como tais ações ocorreram: (1) estudos coletivos e individuais; (2) reunião para preparar e planejar o processo de assimilação mental dos conceitos (ações de ensino que organizam as ações de aprendizagem); (3) registros dos encontros pela pesquisadora e (4) notas reflexivas da professora sobre o realizado.

Os objetivos de tais ações foram: (1) analisar os pressupostos teórico-metodológicos que sustentam a organização do ensino sob a THCA (PUENTES; LONGAREZI, 2017); (2) identificar os pressupostos teórico-metodológicos da DD nas ações de ensino; e, (3) organizar o processo de formação das ações mentais a ser realizado pelos estudantes, de acordo com esses pressupostos (FRANCO, 2015).

Por conseguinte, o movimento que essa IDF revela se distancia, em sua essência (teórico-metodologicamente), de ações externas de alguém que queira sanar algum tipo de problema para o outro. Contrariamente, o referido procedimento visa contribuir para a formação de sujeitos ativos e criativos de seu próprio desenvolvimento, mediados por referenciais teórico-metodológicos e pela prática social, tendo em vista apropriações e objetivações mais humanizadoras e menos alienantes, no ensino e no estudo. Portanto, num movimento dialético espiralar e ascendente. Ascendente, não no sentido de superior, mas no sentido de qualitativamente diferente de formação humano-social dos envolvidos; ou seja, na esfera da formação do sentido pessoal de tais atividades. Para Leontiev (1978), quando a necessidade se satisfaz no objeto, encontra-se em um nível psicológico; por isso, a necessidade objetivada é compreendida como motivo, aquele que forma o sentido pessoal de tal atividade. 
O contexto do episódio As dificuldades de organização do ensino para além da lógica formal refere-se a um dos encontros de formação sobre o ensino da álgebra na THCA (PUENTES; LONGAREZI, 2017) e na DD, suscitados pela pesquisa de Scarlassari (2007) e Rosa (2009). Naquela oportunidade, discutia-se como as autoras trabalharam as situações problemas desafiadoras com os estudantes. A operação (leitura de um texto) e as ações de análise realizadas pela professora para “[...] levantar o princípio ou modo universal [...]” (SEMENOVA, 1996, p. 166) do conceito de equação no nível teórico, encontram-se relacionadas com o conteúdo objetal da atividade (organização do ensino), pela análise de outras experiências do modo de atuação (FRANCO, 2015; LONGAREZI; FRANCO, 2016, 2017).

As discussões de textos sobre a álgebra no enfoque da THCA (PUENTES; LONGAREZI, 2017), uma das operações criadas, desencadeia na professora uma situação conflitiva e contraditória. Quando a professora analisa a história de construção dos conceitos inerentes ao campo da álgebra e também sua significação social, bem como o nível de generalização e abstração que tais conceitos envolvem, percebe que ensinar somente as fórmulas das representações algébricas e suas resoluções não possibilita ao estudante o entendimento das características internas do conceito (FRANCO, 2015). Tudo isso gera muito desconforto, pois, apesar de sempre ensinar bem, nunca havia pensado em como é que o estudante se apropria de conceitos teóricos, ou em como poderia ensiná-los a operar mentalmente, pois, segundo seu ponto vista,

\footnotetext{
O aluno só vai assimilar se o professor tiver essa paciência de ensinar [...] Quanto ao ensino eu acho que é um programa que eu tenho que cumprir, já os conteúdos, é o planejamento dos conceitos em si, e o desenvolvimento é eu conseguir desenvolver dentro da sala de aula o mínimo para que o meu aluno aprenda (FRANCO, 2015, p.166).
}

Pelo exposto, suas concepções de ensino, aprendizagem e desenvolvimento se confrontam com os pressupostos estudados da THCA (PUENTES; LONGAREZI, 2017) e DD, que a colocam frente a um problema conflitante e contraditório que precisa resolver, tendo em vista sua necessidade de entender como seria esse modo de atuação e a necessidade de cumprir o programa curricular do contexto escolar. A professora indaga: “[...] Então, como é que eu faço? Se eu ficar retomando princípios e matérias do ano passado eu não vou conseguir prosseguir com o conteúdo" (FRANCO, 2015 p. 188). Esse argumento revela o quanto, nas escolas, muitas vezes, a preocupação pedagógica concentra-se mais no ensino dos conteúdos curriculares do que no processo de orientar o estudante para operar mentalmente com os conceitos, em um tipo de ensino que impulsione o desenvolvimento integral do sujeito. Nesse caso, a professora se depara com um problema didático e formativo que apenas seus conhecimentos e sua experiência docente não são suficientes para ajudá-la a superar. Isso gera novas necessidades diante de sua atividade de ensino.

Entretanto, a necessidade impulsiona o movimento formativo que pode realizar-se em seu objetivo correspondente: a organização didática do ensino de matemática, pela via da formação das ações mentais no estudante. Por sua vez, tal correspondência pode efetivarse mediante um processo de ações e relações mediadas intencionalmente para esse objetivo. Naquele momento depreendeu-se como unidade de análise que o compartilhamento e as

\section{4}

Ciênc. Educ., Bauru, v. 25, n. 3, p. 705-723, 2019 
interações entre a professora, a pesquisadora e a realidade concreta fomentam o movimento formativo. Nele, o diálogo e as análises sobre a prática pedagógica favorecem o confronto entre o tipo de organização do ensino focado no pensamento empírico e no teórico, e também trazem os dilemas da estrutura do programa curricular oficial de Minas Gerais vivenciados pela professora e por estudantes na escola. A necessidade de pensar sobre como organizar esse processo para orientar o estudante na apropriação teórica do conceito passa a orientar suas ações na IDF. Por isso, as interações entre os sujeitos que, juntos, compartilham seus problemas podem lhes possibilitar estabelecer objetivos em comum para resolvê-los.

Nesse movimento de análises e sínteses sobre a sua atividade de ensinar, sobre as pressões do contexto, sobre seus limites e dos seus estudantes, podem-se perceber os indícios do seu comportamento e do curso de sua necessidade imaterial ao pensamento conceitual, pois, na compreensão da professora, os estudantes “[...] não se envolvem muito, não perguntam nada sobre o que não sabem, e assim, fica difícil para o professor. Mas, acho que a gente pode tentar" (FRANCO, 2015, p. 189). Fica aqui evidenciada a gênese de uma necessidade docente orientada por interesse interno relacionado com o conteúdo e o objetivo do ensino: a organização didática e intencional do ensino para o desenvolvimento.

Nesse caso, depreende-se a atribuição de um sentido pessoal à significação social do ensino, não como um fim em si mesmo, mas como uma condição necessária para que os estudantes se envolvam (tenham motivos) e desenvolvam o pensamento e novas atitudes diante do objeto a conhecer. A atribuição de sentido aos processos de ensino, aprendizagem e desenvolvimento, nesse caso, fez com que alguns elementos de apropriação e objetivação de um ensino para a formação de pensamento e conceitos teóricos se manifestassem em sua prática pedagógica: “[...] Após essa leitura organizei uma aula (com outra turma de alunos não participantes da pesquisa) falando inicialmente sobre esse movimento da álgebra na vida, relacionando-a com o limite corpóreo do homem, com a dança, com o movimento das coisas no mundo, no universo" (FRANCO, 2015, p. 193).

O procedimento de IDF possibilita a atividade compartilhada e desperta o olhar da professora para os aspectos internos do método de ensino e aprendizagem, salientados por Klingberg (1978, p. 292) como aqueles procedimentos e operações lógicas mais propensos a impulsionar a atividade criadora e independente dos estudantes. Desse modo, no domínio consciente e voluntário da forma de organizar o processo de formação das ações mentais nos discentes, a professora consegue se desenvolver de forma psíquica e exercer seu potencial criador no trabalho, na prática pedagógica.

Ainda segundo a professora:

Na graduação em matemática eu não estudei sobre isso, tudo era ensinado de uma forma tradicional mesmo. Então, da mesma forma que eu aprendi comecei a fazer com meus alunos, até porque nem nos cursos de formação continuada não há essa preocupação. Se o professor sabe o conteúdo, então, ele sabe ensinar. (FRANCO, 2015, p. 190).

Nota-se que, caso o conflito gerado naquele contexto não fosse mediado pelas características internas do conceito que pode formar o pensamento teórico da professora sobre o ensino desenvolvimental e se não fosse desenvolvido por meio de ações, formas lógicas e 
abstratas desse tipo de pensamento, poderia resultar somente na reprodução mecânica dessas informações.

A professora analisa resultados de estudos realizados por outros profissionais de matemática no processo de formação das ações mentais de estudantes, a partir da essência dos conceitos a serem constituídos no processo, e não somente pelos conteúdos de ensino. Esse olhar para as investigações e pesquisas já desenvolvidas em sua área de ensino, como as de Rosa (2009) e Scarlassari (2007), dentre outros, lhe possibilita realizar processos de análise e sínteses da teoria e da prática de ensino no campo da álgebra. Tal movimento oferece a possibilidade de identificar, nas pesquisas, a ideia do movimento presente no conceito de álgebra expresso nas situações de ensino propostas por outros pesquisadores. Isso favorece um confronto teórico-prático com o seu entendimento e conhecimento sobre o ensino de álgebra, adquirido ao longo de sua trajetória profissional, e contribui com o seu processo de atribuição de sentido diante da essência do conceito: “[...] Interessante é ver que os exemplos usados por ela, nessa pesquisa, pretendem ajudar o aluno entender o significado dessa linguagem simbólica usado nas equações" (FRANCO, 2015, p. 192). Identifica-se que a forma de ensinar o conceito passa a ser observada por ela, e não mais somente o conteúdo.

Esse movimento aproxima-se das proposições de Galperin (2001) sobre a etapa material e materializada do processo de apropriação de conceitos. No caso do processo formativo docente, compreende-se da seguinte forma: tanto a representação que se tem da prática pedagógica quanto a própria prática pedagógica na sua realidade concreta são pontos importantes a considerar no processo de intervenção didático-formativo docente.

A partir dessa materialização, a professora passa a identificar, em si mesma, seu próprio movimento de formar conceitualmente uma nova abordagem de ensino, as ações realizadas e necessárias para se apropriar dessa perspectiva teórica. Então, vivencia o processo de reelaboração dos conhecimentos e os conceitos matemáticos adquiridos ao longo de sua trajetória formativa e profissional. Nesse processo ocorrem os confrontos entre o real e o ideal, entre o imediato e o mediado. Esses movimentos geram desconfortos, mas ao mesmo tempo são significativos para rever suas convicções, concepções de ensino e aprendizagem. E assim ela relata:

Eu sei, que muitas coisas que eu ensinei até hoje foi de forma muito mecânica. Mas a gente foi educada assim. Não aprendi a pensar sobre o conceito e muito menos ensinar o aluno a fazer isso. A gente vê que os gregos não pensavam assim?! Porque que é tão difícil para o aluno entender a linguagem simbólica da equação? (FRANCO, 2015, p. 205).

Nesse tipo de apropriação/objetivação, a professora começa conscientizar-se tanto das suas condições alienadoras diante do conceito teórico quanto do seu potencial para superá-las: "Então, eles precisam entender que uma equação representa uma situação de igualdade, equivalência e que há também outra característica muito importante, o campo de variação" (FRANCO, 2015, p. 195). Tais sínteses compartilhadas e individuais abrem caminhos para a compreensão dos nexos conceituais, entendidos "como elo entre as formas de pensar o conceito” (SOUSA, 2004, p. 53). A autora afirma que fluência, campo de variação e variável são os nexos que formam o conceito de álgebra. 
Pode-se dizer que a docente não exclui o que sabe de seu campo de conhecimento, mas o coloca sob novas indagações, uma vez que se estabelece uma tensão dialética entre seu modo de conduzir o ensino e o que almeja em um ensino para o desenvolvimento do pensamento teórico e apropriação de conceitos teóricos. Isso significa dizer que ela busca os instrumentos e os meios capazes de proporcionar aos estudantes as condições de colocar-se em atividade, de ser mais ativos, e não passivos, no processo de apropriação conceitual.

Nesse percurso, Franco (2015, p. 269) esclarece:

[...] no caso do conceito de 'função' o estudante apropriou-se da essência de seu movimento, partindo primeiro de seus traços gerais (de relações de interdependência entre duas grandezas que se variavam, e da regularidade quantitativa), e destes, ele conseguiu extrair os seus traços particulares (movimento entre as variáveis dependentes e independentes, o tipo de grandeza a que se referiam: segmento ou de área). Considerando os pressupostos de Vigotski (2001, p. 269), entendemos que, para a maioria dos estudantes esses conceitos se desenvolveram, no campo da álgebra, mediados pelas generalizações precedentes da aritmética e da geometria. Isso ocorreu, porque as operações lógicas com esses conceitos consideram-se casos particulares de um conceito mais geral (álgebra), e a operação lógica do pensamento com eles, nesse caso, vai ocorrer de forma mais livre.

Observe-se que primeiro a professora precisa compreender e se apropriar da essência e dos nexos que compõem o dado conceito, para depois orientar seus estudantes nessa apropriação teórica, no campo da álgebra. Pelos indícios apresentados nos episódios, ela consegue realizar movimentos de apropriação teórica sobre a docência, em seus elementos didáticos e formativos, ainda que em meio às contradições, às limitações curriculares e às legislações educacionais vigentes no País, bem como nas condições socioculturais dos estudantes.

Em decorrência dessa IDF, apreendem-se algumas ações didáticas impulsionadoras do desenvolvimento dos sujeitos, as quais, de certa forma, ajudam a compor a discussão sobre a formação docente e discente como unidade teórico-prática e conteúdo-forma, objetivo deste artigo, tendo em vista responder a sua questão nuclear: Que ações didáticas mobilizam o desenvolvimento de motivos formadores de sentido, no ensino e no estudo, potencializadores da bumanização da professora $e$ dos estudantes na educação escolar?. No contexto da investigação realizada, apreendem-se algumas ações didáticas:

1) Organizar o ensino propiciando, aos estudantes, as condições, as ferramentas da cultura e os modos de ações mentais lógicas e específicas, tendo em vista a apropriação de conceitos teóricos;

2) Analisar o conceito, descobrir a sua essência, a sua lógica interna para estabelecer finalidades e planejar as ações que possibilitam tanto a orientação como a regulação do processo, de forma clara e ativa pelo próprio sujeito em formação; 
3) Promover a autonomia e a criação do professor diante dos processos de análise de sua prática pedagógica, ou seja, diante da preparação e organização de um ensino que promova o desenvolvimento;

4) Considerar o sistema de relações no contexto escolar e os interesses que decorrem desse campo, os quais incidem sobre os aspectos cognoscitivos, volitivos e afetivos dos sujeitos (FRANCO, 2015, p. 274).

Essas ações didáticas não podem ser vistas como receituário ou técnica: constituem resultados apreendidos do movimento realizado com determinados sujeitos, que salientaram como ponto de partida o conhecimento, a experiência e a vivência da professora e de estudantes, sujeitos históricos em um contexto escolar e cultural específico. Ao considerar esse ponto de partida, a IDF desencadeia os movimentos de confrontos da professora consigo, com a realidade e com a teoria, para a superação da dicotomia entre ser e essência, no espaço propício de escolarização e humanização, a escola. Portanto, em cada situação e contexto há necessidades objetivas e subjetivas, condições distintas de formação e ação docente, bem como discente.

\section{Considerações finais}

Com o objetivo de discutir a formação docente e discente como unidade teórico -prática e conteúdo-forma, buscou-se entender em quais condições seria possível estabelecer outras relações na estrutura interna das atividades de ensino e de estudo em contextos escolares públicos brasileiros, tendo em vista o desenvolvimento de novos motivos formadores de sentido, como orienta a concepção leontieviana. Com tal aporte, se o motivo é o que orienta o sujeito numa determinada atividade, deve ser também aquilo que coincide com o seu próprio objeto, com seu conteúdo; caso contrário, ocorre uma cisão entre significado e sentido da própria atividade, que deixa de existir.

Nessa perspectiva, o procedimento de IDF esteve mediado por conceitos científicos sobre a docência na sua relação com o trabalho educativo. Dito de outra forma, esse processo se constituiu, considerando a unidade das atividades de ensino, aprendizagem e desenvolvimento. Os confrontos e os conflitos sobre o processo do conhecimento científico, provenientes da lógica formal e da lógica dialética, colocaram a professora em movimento de busca por referenciais, tendo em vista a formação e o desenvolvimento de novas formas de pensamento conceituais. Esse se constituiu no sentido da unidade teórico-prática e conteúdo-forma na formação docente e discente. Dimensões que não se excluíram durante o processo, mas operaram entre si de forma diferente, em um movimento que se efetivou do abstrato ao concreto, numa relação dinâmica e dialética.

As ações analíticas da professora sobre pesquisas desenvolvidas no campo da matemática, especificamente no campo da álgebra, com o aporte do ensino e da didática desenvolvimental e a realidade da sala de aula, proporcionaram à professora a materialização do processo. Essa materialização ocorreu mediada pela própria atividade (trabalho pedagógico), por interações entre os sujeitos, a teoria e a realidade. De modo que essa ação, articulada às ações de verbalização sobre os objetivos do ensino e da pesquisa, favoreceu os momentos de 
sínteses e apropriações teóricas, tendo em vista objetivações mais humanizadoras de si mesma e de seus estudantes na realidade concreta da aula. Quando, na IDF, tomou-se a própria prática pedagógica (sua forma material), bem como a representação que se tinha dela (sua forma materializada), a professora conseguiu pensar e refletir sobre ela conceitualmente. Isso favoreceu à professora a constituição de instrumentos para colocar-se em condição de atividade.

A lógica de superação da perspectiva marxista na formação docente e discente discutida neste texto pode ser entendida como algo que, enquanto novo superado, não elimina o velho, mas o contempla sob outra perspectiva. O pensamento conceitual sobre a docência não elimina a sua forma material, mas a contempla sob a ótica da abstração. Além disso, essa lógica de formação possibilita um novo olhar sobre a organização dos processos formativos docentes, na medida em que considera o potencial da professora e a organização do ensino como conteúdo e forma das ações formativas para si mesma e de seus estudantes. Portanto, favorece um tipo de desenvolvimento qualitativo no trabalho educativo da professora em seu aspecto profissional, bem como no sentido pessoal da atividade de ensino em sua vida docente.

Os resultados evidenciam os movimentos de superação teórico-prática da professora em sua atividade de ensino, ao criar e organizar novas ações de aprendizagem impulsionadoras de desenvolvimento qualitativo do pensamento teórico dos estudantes. Do movimento de superação da professora no contexto de sua docência se processa um desenvolvimento qualitativo teórico-prático, profissional-pessoal, que evidencia o potencial de humanização do processo didático-formativo. As discussões apresentadas buscam fomentar o interesse de outros pesquisadores e de investigações pelo processo constituído, com vistas à superação de práticas dicotômicas de formação docente e discente, muitas vezes, constituídas a partir de situações alienantes e alienadoras dos sujeitos em relação ao seu potencial humano, criativo e científico diante da realidade social.

\section{Agradecimentos}

O texto apresenta dados de pesquisas desenvolvidas com apoio do Conselho Nacional de Desenvolvimento Científico e Tecnológico (CNPq, Processo no 120084/2016-3), do Observatório da Educação Básica (OBEDUC), da Coordenação de Aperfeiçoamento de Pessoal de Nível Superior (Capes) e da Fundação de Amparo à Pesquisa do Estado de Minas Gerais (Fapemig).

\section{Referências}

ALVARADO PRADA, L. E. Formação participativa de docentes em serviço. Taubaté: Cabral Editora Universitária, 1997.

ALVARADO-PRADA, L. E.; FREITAS, T. C.; FREITAS, C. A. Formação continuada de professores: alguns conceitos, interesses, necessidades e propostas. Diálogo Educacional, Curitiba, v.10, n. 30, p. 367-387, 2010. 
Franco, P. L. J.; Longarezi, A. M.; De Marco, F. F.

CORAGGIO, J. L. Propostas do Banco Mundial para a educação: sentido oculto ou problemas de concepção? In: TOMMASI, L.; WARDE, M. J.; HADDAD, S. (org.). O Banco Mundial e as políticas educacionais. São Paulo: Cortez, 1996. p. 75-124.

DAVYDOV, V. V. La enseñanza escolar y el desarrollo psíquico. Moscú: Editorial Progreso, 1988.

FEROLA, B. C. Contribuições para a didática desenvolvimental no ensino médio: ações didáticas para a formação de conceitos científicos em biologia. 2016. 74 f. Trabalho de conclusão de curso (Licenciatura em Ciências Biológicas) - Universidade Federal de Uberlândia, Uberlândia, 2016.

FERREIRA, I. M. Aprendizagem e desenvolvimento infantil na perspectiva da didática desenvolvimental. Uberlândia: Programa de Pós-Graduação em Educação: Universidade Federal de Uberlândia, 2017a. (Projeto de pesquisa não publicado).

FERREIRA, I. M. S. Intervenção didático-formativa: uma possibilidade metodológica no campo da pesquisa em didática. In: ENCONTRO ESTADUAL DE DIDÁTICA E PRÁTICA DE ENSINO, 2017, Goiânia. Anais [...]. Goiânia: IFGoiano, 2017b.

FERREIRA, I. M. S. A intervenção didático-formativa no campo da pesquisa em didática desenvolvimental. In: COLÓQUIO GEPAPE, 2017, Goiânia. Caderno de resumos [...]. Goiânia: UFG, 2017c.

FERREIRA, I. M. S. A intervenção didático-formativa na pesquisa em didática desenvolvimental. COLÓQUIO INTERNACIONAL ENSINO DESENVOLVIMENTAL: SISTEMA ELKONIN DAVIDOV, 4., 2018, Uberlândia. Anais [...]. Uberlândia: EDUFU, 2018.

FRANCO, P. L. J. O desenvolvimento de motivos formadores de sentido no contexto das atividades de ensino e estudo na escola pública brasileira. 2015. $363 \mathrm{f}$. Tese (Doutorado em Educação) - Universidade Federal de Uberlândia, Uberlândia, 2015.

FRANCO, P. L. J. Significado social e sentido pessoal da formação continuada de professores: o caso de Ituiutaba/MG. 2009. 231 f. Dissertação (Mestrado em Educação) Universidade de Uberaba, Uberaba, 2009.

FRANCO, P. L. J.; LONGAREZI, A. M. Elementos constituintes e constituídores da formação continuada de professores: contribuições da teoria da atividade. Educação e Filosofia, Uberlândia, v. 25, n. 50, p. 557-582, 2011.

FRANCO, P. L. J.; SOUSA, W. D. D. Didáticas específicas à luz da teoria histórico-cultural. Obutchénie, Uberlândia, v. 2, n. 2, p. 302-313, 2018.

FRANCO, P. L. J.; LONGAREZI, A. M.; MARCO, F. F. Fundamentos teóricometodológicos de ações didático-formativas no contexto da docência em matemática. In: CYRINO, M. C.C. T. (org.). Temáticas emergentes de pesquisas sobre a formação de professores que ensinam matemática: desafios e perspectivas. Brasília: SBEM, 2018. p. $174-190$. 
FRANCO, P. L. J.; LONGAREZI, A. M.; MARCO, F. F. Motives in Brazilian school education according to the cultural historical perspective and the developmental education approach. Nauchnyi Rezul'tat: seriya pedagogika i psikhologiya obrazovaniya, Belgorod, v. 3, n. 3, p. 51-57, 2017.

FRANCO, P. L. J.; LONGAREZI,; MARCO, F. F. Organização do ensino de matemática como conteúdo e forma do processo formativo à luz da teoria histórico-cultural. In: CONGRESSO NACIONAL DE EDUCAÇÃO, 12., 2015, Curitiba. Anais [...]. Curitiba: PUCPR, 2015. p. 2507-2521.

FRANCO, P. L.J; LONGAREZI, A. M.; MARCO, F. Organização do ensino de matemática na perspectiva histórico-cultural: um processo didático-formativo. Zetetiké, Campinas, v. 24, n. 45, p. 127-140, 2016. DOI: https://doi.org/10.20396/zet.v24i45.8646533.

FRANCO, P. L. J.; SOUZA, L. M. A.; FEROLA, B. C. Princípios didáticos e movimentos para uma "Obutchénie por unidades". Linhas Críticas, Brasília, v. 24, ahead of print, p. 475-497, 2019. DOI: https://doi.org/10.26512/lc.v24i0.19820.

FREITAS, L. C. Em direção a uma política de formação de professores. Em Aberto, Brasília, v. 12, n. 54, p. 3-22, 1992.

GALPERIN, P. Y. Sobre La formación de los conceptos y de lãs acciones mentales. In: GALPERIN, P. Y. La formación de las funciones psicológicas durante el desarrollo del niño. Tlaxcala de Xicohténcatl: Universidade Autonoma de Tlaxcala, 2001. p. 45-56.

GERMANOS, E. Contradições como força de mudança: o processo de formação continuada de professores do ensino médio enquanto potencializador da práxis transformadora à luz da teoria histórico-cultural. 2016. 330 f. Tese (Doutorado em Educação) - Faculdade de Educação, Universidade Federal de Uberlândia, Uberlândia, 2016.

KLINGBERG, L. Introducción a la didáctica general. La Habana: Editorial Pueblo y Educación, 1978.

LEONTIEV, A. N. Problemas del desarrollo del psiquismo. 2. ed. La Habana: Editorial Pueblo y Educación, 1974.

LEONTIEV, A. N. O desenvolvimento do psiquismo. Lisboa: Horizonte Universitário, 1978.

LEONTIEV, A. N. O desenvolvimento do psiquismo. São Paulo: Editora Moraes. 1978.

LEONTIEV, A. N. Acerca de la importancia del concepto de actividad objetal para la psicología. In: QUINTANAR ROJAS, L. La formación de las funciones psicológicas durante el desarrollo del niño. Tlaxcala de Xicohténcatl: Universidad Autónoma de Tlaxcala, 2001. p. 15-26.

LONGAREZI, A. M. Didática desenvolvimental no contexto da escola pública brasileira: modos e condições para um ensino que promova o desenvolvimento. Brasília: CAPES, 2012. (Programa Observatório da Educação, projeto de pesquisa não publicado). 
Franco, P. L. J.; Longarezi, A. M.; De Marco, F. F.

LONGAREZI, A. M. Didática desenvolvimental: intervenções pedagógico-formativas desenvolvedoras de estudantes do ensino fundamental, médio e superior. Brasília: CNPq, 2014. (Projeto de pesquisa não publicado).

LONGAREZI, A. M. Para uma didática desenvolvimental e dialética no contexto de escolas públicas brasileiras. Revista Obutchénie, Uberlândia, v. 1, n. 1, p. 187-230, 2017. DOI: https://doi.org/10.14393/OBv1n1a2017-9.

LONGAREZI, A. M., FERREIRA, I. M. S. Pesquisas com formação de professores em didática desenvolvimental: uma intervenção didático-formativa. In: LIMONTA, S. (org.). Trabalho docente e pesquisa com professores. Goiânia: Ed. da UFG, 2019 (no prelo).

LONGAREZI, A. M.; FRANCO, P. L. J. Atividade pedagógica na unidade significado socialsentido pessoal. In: LONGAREZI, A. M.; VALDÉS PUENTES, R. (org.). Fundamentos psicológicos e didáticos do ensino desenvolvimental. Goiânia: EDUFU, 2017. p. 265290.

LONGAREZI, A. M.; FRANCO, P. L. J. Educação escolar enquanto unidade significado social/sentido pessoal. Nuances: estudos sobre educação, Presidente Prudente, v. 24, n. 1, p. $92-109,2013$.

LONGAREZI, A. M.; FRANCO, P. L. J. A formação-desenvolvimento do pensamento teórico na perspectiva histórico-cultural da atividade no ensino de matemática. Revista Educativa, Goiânia, v. 19, n. 2, p. 526-561, 2016.

LONGAREZI, A. M.; MOURA, M. O. Intervenção didático-formativa como procedimento de pesquisa com ensino deenvolvimental. In: SIMPÓSIO DE PÓS-DOUTORADO DA FEUSP, 7. 2017, São Paulo. Anais [...]. São Paulo: FEUSP, 2017.

LONGAREZI, A. M.; PUENTES, R. V. Apresentação. In: LONGAREZI, A. M.; VALDÉS PUENTES, R. (org.). Fundamentos psicológicos e didáticos do ensino desenvolvimental. Goiânia: EDUFU, 2017. p. 7-15.

MOURA, M. O. O educador matemático na coletividade de formação: uma experiência com a escola pública. 2000. Tese (Livre-Docência em Educação) - Universidade de São Paulo, São Paulo, 2000.

PETROVSKI, A. Psicología general: manual didáctico para los institutos de pedagogía. 3. ed. Moscú: Editorial Progreso, 1986.

PUENTES, R. V.; LONGAREZI, A. M. A didática desenvolvimental: seu campo conceitual na tradição da psicologia histórico-cultural da atividade. In: LONGAREZI, A. M.; VALDÉS PUENTES, R. (org.). Fundamentos psicológicos e didáticos do ensino desenvolvimental. Goiânia: EDUFU, 2017. p. 187-224.

RODRIGUES, A.; FRANCO, P. L. J.; BUÊNCIO, J. R. Contribuições do sistema didático Galperin-Talízina para a organização do ensino de geometria. Obutchénie, Uberlândia, v. 2, n. 1, p. 193-213, 2018. 
ROSA, V. M. G. Aprendizagem da equação do $2^{\mathbf{o}}$ grau: uma análise da utilização da teoria do ensino desenvolvimental. 2009. 124 f.Dissertação (Mestrado em Educação) Universidade Católica de Goiás, Goiânia, 2009.

SEMENOVA, M. A. A formação teórica e científica do pensamento dos escolares. In: GARNIER, C.; BERDNARZ, N.; ULANOVSKAYA, I. Após Vyigotsky e Piaget: perspectiva social e construtivista, escola russa e ocidental. Porto Alegre: Artes Médicas, 1996. p. 160-168.

SCARLASSARI, N. T. Um estudo de dificuldades ao aprender álgebra em situações diferenciadas de ensino de alunos da $\mathbf{6}^{\mathbf{a}}$ série do ensino fundamental. 2007.149 f. Dissertação (Mestrado em Educação) - Faculdade de Educação, Universidade Estadual de Campinas, 2007.

SOUSA, M. C. O ensino de álgebra numa perspectiva lógico-histórica: um estudo das elaborações correlatas de professores do Ensino Fundamental. 2004. 250 f. Tese (Doutorado em Educação Matemática) - Faculdade de Educação, Universidade Estadual de Campinas, 2004.

SOUSA, W. D. Processos de imitação-criação como constituidores da práxis pedagógica. 2016. 343 f. Tese (Doutorado em Educação) - Universidade Federal de Uberlândia, Uberlândia, 2016.

SOUZA, L. M. A. A sociologia no ensino médio: princípios e ações didáticas orientadoras de um ensino que possibilite o desenvolvimento de adolescentes em uma perspectiva histórico-cultural. Dissertação (Mestrado em Educação) - Faculdade de Educação, Universidade Federal de Uberlândia, Uberlândia, 2016.

VIGOTSKI, L. S. Obras escogidas. Madri: Visor: MEC, 1991. Tomo 1. 
